\title{
Analysis on the technical and value advantage of server virtualization in college teaching resources informatization
}

\author{
NIE jing ${ }^{1, a}$ \\ ${ }^{1}$ NanNing College For Vocanonal Technology School Of Information Engineening GuangXi, China \\ anj2007@163.com
}

Keywords: virtualization technology; informationization construction; server virtualization

Abstract. The present informatization construction of college teaching resources is confronted with many problems, such as expensive running and maintenance cost, huge expenditure on renewing equipment, rocket-rising cost of human and teaching resources and so on. Server virtualization helps to simplify IT system, increase utilization of IT resources, quickly create and restore teaching environment, and cut down resource consumption.

\section{Introduction}

At present, informatization construction in higher schools has generally changed from infrastructure construction of software and hardware to building platforms and system integration, among which construction of teaching resources database, resource platform, information platform and support platform are of much importance. In the course of realizing college informatization, such advanced technology and idea as virtualization and cloud computing have offered great impetus and played important and infrastructure role.

\section{Problems in college informatization construction}

With the further deepening of college informatization construction, some problems begin to appear. These problems include:

1. expensive running and maintenance cost, huge expenditure on renewing equipment, rocket-rising cost of human and teaching resources;

2. complex infrastructure and uneven distribution of using server resources;

3. non-standard data management and poor data security caused by lack of centralized and unified management;

4. hardware construction coming before software construction.

\section{Precondition of solving the problems}

Virtualization has developed quickly, and all the main OS manufacturers and independent software developers have offered solutions to virtualization. In the field of server virtualization, there are 3 major manufacturers, namely VMware, Microsoft and Citrix Xen. Table 1 show the differences between the virtualized servers of the 3 manufacturers.

\begin{tabular}{|l|l|l|l|}
\hline & VMware & Microsoft & Citrix Xen \\
\hline $\begin{array}{l}\text { Hypervisor } \\
\text { product }\end{array}$ & ESXi(free)/ESX & HyperV Server & Xen Server \\
\hline $\begin{array}{l}\text { VM storage } \\
\text { format }\end{array}$ & $\begin{array}{l}\text { VMDK,OVF(w/VApp } \\
\text { installed) }\end{array}$ & VHD,OVF & VHD,OVF \\
\hline $\begin{array}{l}\text { Guest OS's } \\
\text { supported }\end{array}$ & $\begin{array}{l}\text { Windows,Mac,Linux,others } \\
\text { including DOS 6.22! }\end{array}$ & $\begin{array}{l}\text { Mostiy Windows } \\
\text { Family,Red } \\
\text { Hat,SUSE }\end{array}$ & Windows, Linux \\
\hline $\begin{array}{l}\text { Management } \\
\text { tools }\end{array}$ & $\begin{array}{l}\text { VCenter } \\
\text { VSphere, } \\
\text { vCenter Lab Manager, } \\
\text { vCenter } \\
\text { View Converter. }\end{array}$ & $\begin{array}{l}\text { System Center VM } \\
\text { Manager }\end{array}$ & $\begin{array}{l}\text { Citrix } \\
\text { Essentials,Lab } \\
\text { Manager }\end{array}$ \\
\hline $\begin{array}{l}\text { Hypervisors } \\
\text { managed }\end{array}$ & ESX & $\begin{array}{l}\text { HyperV,ESX orw; } \\
\text { Xen(next release) }\end{array}$ & Xen,HyperV \\
\hline Disadvantages & Pricing and licensing & $\begin{array}{l}\text { Limited multiple CPU } \\
\text { support }\end{array}$ & $\begin{array}{l}\text { Limited pre-buitt } \\
\text { appliances }\end{array}$ \\
\hline
\end{tabular}

Table.1 The differences between the virtualized servers of the 3 manufacturers 
According to Table 1, Microsoft's product is not so good as VMware's product in usability and feasibility, yet its price is more alluring for medium-sized and small enterprises. VMware vSphere takes the lead in construction of large virtual server. It outperforms its competitors in copy and transfer technology of the virtual machine. Its good reliability brings high market share and good reputation.

\section{Solution to server virtualization}

Aiming at the problems and based on actual condition and future extendibility, we choose VMware vSphere as architect solution to server virtualization. Based on cloud computing, VMware vSphere integrate all servers into a resources pool, offering effective, flexible and low-carbon information platforms with good extendibility to higher schools construction. The graph below is the virtualization solution of my college.

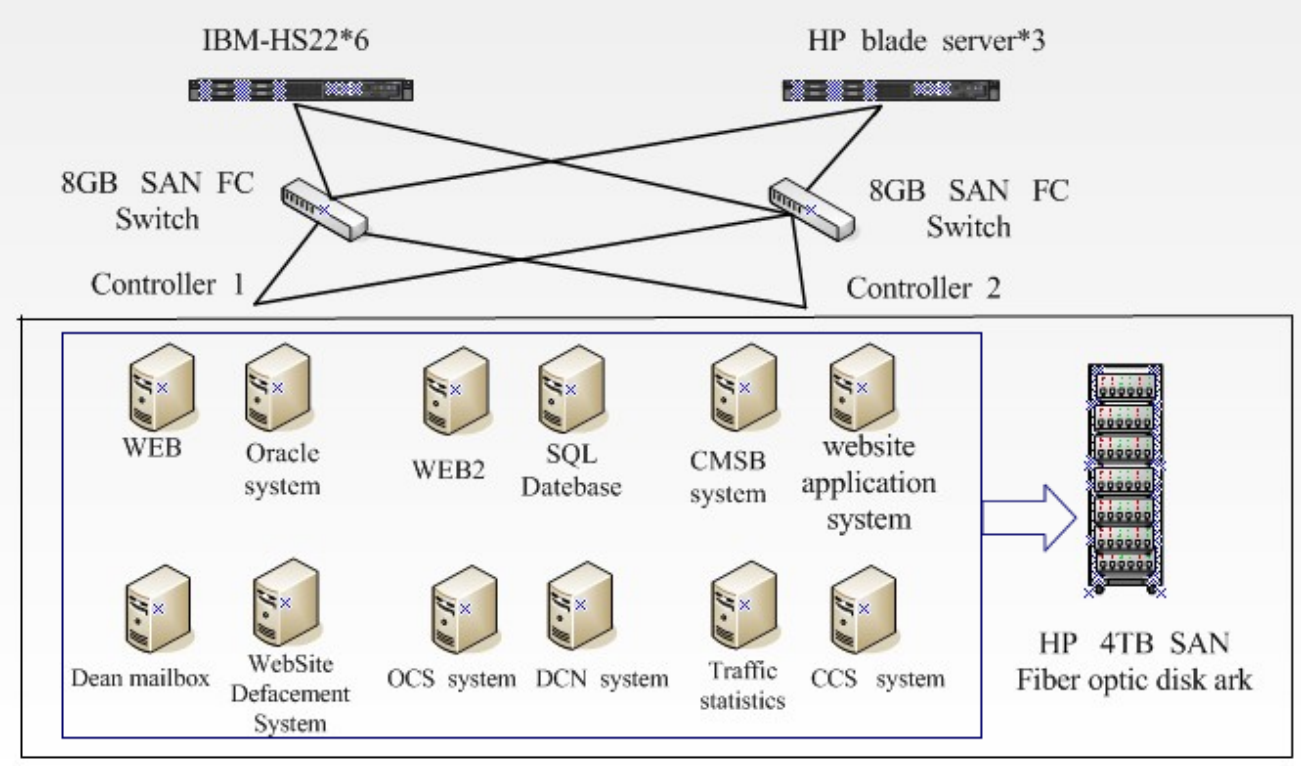

Figure.1 The virtualization solution of my college

Our computing cluster is made up of 6 IBM HS22 blade servers and 3 HP blade servers (each server equipped with 1-2 six core XEON 5650 2.66Ghz CPU and 24G internal memory), thus the computing cluster has 72 CPUs, and its total CPU calculating speed and total internal memory reach 191.52Ghz and 216G respectively. The application network of the cluster is made up of Ethernet with a speed of $1000 \mathrm{M}$, and the data network is made up of SAN fiber optic network with a internal memory of 8GB. Through a high speed of 8GB and MPIO redundancy multipath optical fiber channel, the 9 blade servers are connected to a 4TB HP SAN disk cabinet. It changed the practice in the original server that virtual machines were all stored in local hard disk. Besides it greatly increase the usage of servers' resources. Some serious problems such as scheduling servers' resources, insufficient storage place and dysfunction of discs, and system failing to offer regular service caused by server's fault. It has successfully built a highly available platform for sharing resource servers which can realize unified management and control of computing resources, and easy maintenance and supervision.

Below are technical and value advantages of VMware vSphere.

1. it simplifies the IT system, schedules resources dynamically, and keeps business continuity and the IT system available all the time, and increases resources efficiency. 

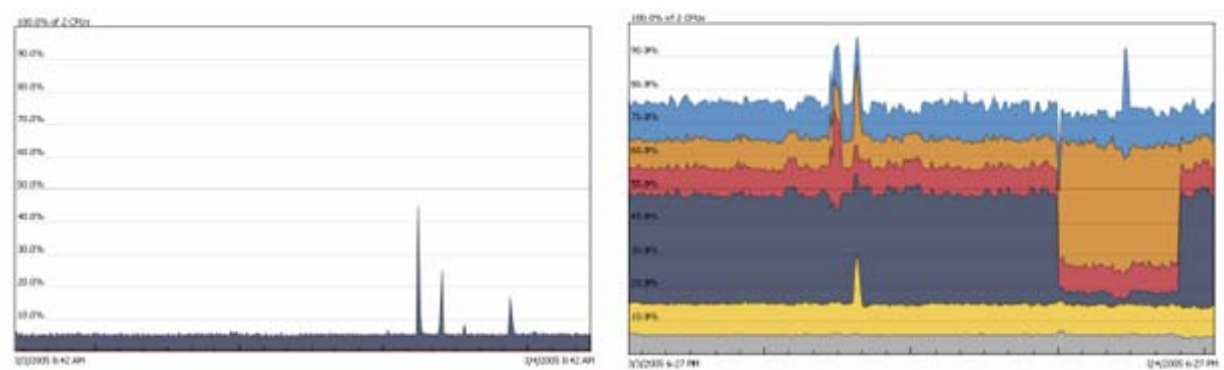

Figure.2 Cpu usage before and after comparison

Using the server virtualization technology on the basis of the original application, focusing on a single physical machine greatly increases the utilization rate of the physical resources, and accordingly reduce the investment on hardware,

2.VMware vSphere technology unifies the management, improves security and data protection capability, and is excellent in terms of stability and safety etc..

After the employment of virtualization, disaster recovery will become rather easy. Using the latest snapshot of the virtual machine, the system can recover quickly. And once a disaster takes place in data center, the system can also move the virtual machine to any other places.

3.VMware vSphere technology facilitates the fast and safe creation of teaching resources, which is easy to deploy and recover the teaching environment

In general, the deployment of college server facing the following challenges: 1、Depending on the availability of hardware 2、Prone to human error 3、 Difficulty in standardization 4、 a few days, even weeks needed. While the adoption of the server virtualization technology the deployment can be accomplished by simply entering active configuration parameters, copying the virtual machine, starting the virtual machine, activating the virtual machine without manual intervention. The deployment time is greatly shortened. The deployment cost is reduced.

4. When the core technology is grasped, special service can be offered to each user according to their needs, which helps to cut down the cost and is environmentally-friendly.

Presently, many desktops and servers work in $8 \%-15 \%$ the time after they are started, mostly they are idle. Even so they can still consume $60 \%-90 \%$ powers compared with that consumed when they are busy.

\begin{tabular}{|c|c|c|c|c|c|}
\hline \multicolumn{3}{|c|}{ Before integration } & \multicolumn{3}{|c|}{ After integration } \\
\hline application & Server number & Power & application & Server number & Power \\
\hline ASystem & 1 & $0.6 \mathrm{~kW} / \mathrm{h}$ & ASystem & \multirow{6}{*}{5} & \multirow{6}{*}{$3 \mathrm{~kW} / \mathrm{h}$} \\
\hline BSystem & 1 & $0.6 \mathrm{~kW} / \mathrm{h}$ & BSystem & & \\
\hline CSystem & 1 & $0.6 \mathrm{~kW} / \mathrm{h}$ & CSystem & & \\
\hline DSystem & 1 & $0.6 \mathrm{~kW} / \mathrm{h}$ & DSystem & & \\
\hline ESystem & 1 & $0.6 \mathrm{~kW} / \mathrm{h}$ & ESystem & & \\
\hline other & 5 & $3 \mathrm{~kW} / \mathrm{h}$ & other & & \\
\hline Year Total & 10 & $52560 \mathrm{~kW}$ & \multirow{2}{*}{\multicolumn{2}{|c|}{$\begin{array}{l}\text { Reduce power } \\
\text { consumption } \quad 50 \%\end{array}$}} & $26280 \mathrm{~kW}$ \\
\hline & & & & & \\
\hline
\end{tabular}

Figure.3 Saving energy and cutting down energy consumption (of servers)

\section{Conclusion}

It is the virtualization and cloud computing age now. Higher schools, government departments and enterprises are advocates of advanced technology and ideas such as virtualization and cloud computing in the course of informatization. How to deal with challenges brought by virtualization and cloud computing, grasp the opportunity, and catch up with the development of future IT technology has become a concern in college informatization. VMware vSphere has offered an 
effective, flexible, safe and controllable solution for higher schools' informatization construction. Virtualization has a bright application prospect in future college informatization construction, while VMware vSphere, close to the need of colleges and universities, provides strong technical support for higher schools to realize informatization.

\section{References}

[1] Server virtualization in the role of information technology. http://www.toberp.com/html/consultation/1083967099.html

[2] VMware vSphere cloud operating system http://www.soft6.com/news/200911/20/161174.html

[3] VMware vSphere 5 HA Comments http://delxu.blog.51cto.com/975660/717516

[4] Server Load Balancing: VMware DRS vs. Microsoft SCV http://virtual.51cto.com/art/201105/261309.htm

[5]D.F.Carr.How Google works. Baseline Magazine,July 2006 